"Cool Kids" in Denmark: Commentary on a

Commentary on $A$ "Cool Kids" Cognitive-Behavioral Therapy Group for Youth with Anxiety Disorders: Part 1, The Case of Erik, and Part 2, Analysis of the Process and Outcome of Responders Versus Nonresponders

\title{
"Cool Kids" in Denmark: Commentary on a Cognitive-Behavioral Therapy Group for Anxious Youth
}

\author{
SARAH J. PERINI ${ }^{\text {a }}$, VIVIANA M. WUTHRICH ${ }^{\text {a }}$, \& RONALD M. RAPEE ${ }^{\text {a,b }}$ \\ a Centre for Emotional Health, Department of Psychology, Macquarie University, Sydney, Australia \\ b Correspondence regarding this article should be addressed to Ron Rapee, Centre for Emotional Health, \\ Department of Psychology, Macquarie University, Sydney, NSW, Australia, 2109. \\ Email: Ron.Rapee@mq.edu.au
}

\section{ABSTRACT}

Two case studies by Lundkvist-Houndoumadi and Thastum (2013a, 2013b) describe the use of the Cool Kids cognitive behavioral therapy program for anxious children and their parents, which was conducted at their Clinic at the University of Aarhus in Denmark. In providing our reactions to these two fascinating and illuminating articles, we first familiarize readers with the Cool Kids program, including both its nature, range, and evidence base. This is followed by a discussion of some relevant issues and complications in doing therapy with anxious children that are illustrated by these case studies, including the motivation of both anxious children and their parents; the therapeutic role of exposure to anxious situations; a modular approach to accommodate individual variation; group versus individual format; directly addressing parental anxiety problems; and the cost-effectiveness of treatment.

Key words: child anxiety; adolescent anxiety; treatment; Cool Kids; case studies; clinical case studies

\section{INTRODUCTION TO THE COOL KIDS PROGRAMS}

In this commentary on two case study articles by Lundkvist-Houndoumadi and Thastum (2013a, 2013b), we first review as context the nature, range, and supporting evidence for the Cools Kids model for cognitive behavior therapy with anxious youth and their parents. Then we explore a number of issues and complications in doing such therapy that are highlighted by the Lundkvist-Houndoumadi and Thastum case studies

The Cool Kids suite of manuals encompasses a series of evidence based psychological therapy programs for the treatment of primary anxiety (and depression in the adolescent Chilled program ([Schniering, Rapee, Lyneham, Wuthrich, Hudson \& Wignall, 2006]) in children aged 3-18 years of age. It has been developed throughout more than 15 years of research and has a strong evidence base from several large randomized controlled trials. Results demonstrate that up to $80 \%$ of children who complete the program are diagnosis-free or markedly improved (Barrett 
"Cool Kids" in Denmark: Commentary on a

Cognitive-Behavioral Therapy Group for Anxious Youth

S.J. Perini, V.M. Wuthrich, \& R.M. Rapee

Pragmatic Case Studies in Psychotherapy, http://pcsp.libraries.rutgers.edu

Volume 9, Module 3, Article 4, pp. 359-370, 10-27-13 [copyright by authors]

et al., 1996; Hudson et al., 2009; Hudson et al., 2013; Rapee et al., 2006). These results have been shown to maintain for up to 6 years (Barrett et al., 2001). The treatment used is primarily skills-based, that is, the aim is to teach young people and their parent(s) specific skills and techniques to help manage their anxiety and the accompanying life impairment. Adaptions to the core program are incorporated to adapt teaching methods and examples for different age groups. Hence slightly different versions are available for preschool children, school aged children, and adolescents. Further adaptations of the program have been developed for anxious populations with specific comorbidities, such as depression (in the adolescent Chilled program) and Autism Spectrum Disorder. A version for anxious children who are experiencing peer victimization, and another for anxious children with sleeping difficulties are currently being developed. Finally, different methods of delivery of the Cool Kids program have been evaluated and are supported by unique manuals. These include individual therapy delivery, family group-based therapy, school-based delivery, and an outreach version that allows delivery of the Cool Kids program to young people who do not attend a clinic (via printed materials or computerized delivery). A summary of the programs is presented in Table 1 and more information on each program, together with supporting evidence, is described below.

Despite the different versions of the program, the underlying principles and core mechanisms are largely the same. The program is heavily based on skills training in cognitive restructuring, graded exposure, and parent management of anxious behaviors. There is also a strong focus on home-based skills practice, and parents and children typically have worksheets to complete between sessions. All of the Cool Kids programs are supported by a guidance manual for the therapist as well as workbooks for the child and the parent(s). Different age-appropriate workbooks are relevant to either children (aged 7-12) or adolescents (aged 13-18). The Cool Kids program is currently widely used both in Australia and internationally. Manuals from the Cool Kids series have been translated into several different languages including: Chinese, Danish, Icelandic, Korean, Spanish, Swedish, Italian, and Turkish.

\section{Cool Kids Anxiety Program (Rapee, Lyneham et al., 2006a)}

The standard Cool Kids program and the original program from which the other versions are based was designed for children aged 7-18 years of age and involves direct therapist contact with both the child and their parent(s), based on standard, clinical delivery. The program teaches parents and children cognitive behavioral therapy skills to manage anxiety through 10 sessions, spread over 12 weeks. Therapist-led sessions can be delivered in either group format (2 hour duration), or individual format (standard 1 hour duration). Content of the program includes a strong focus on psycho-education, cognitive restructuring, graded exposure, and parent management training. Additional modules are included and can be used as needed, including social skills training, improvements in assertiveness, dealing with teasing and bullying, and general coping skills.

The standard Cool Kids program has been evaluated in several large, randomized controlled trials and has shown effects that are significantly better than waitlist, bibliotherapy, and an active placebo (Hudson et al., 2009; 2013; Rapee, 2000; 2003; Rapee et al., 2006; 2013). 
"Cool Kids" in Denmark: Commentary on a

Cognitive-Behavioral Therapy Group for Anxious Youth

S.J. Perini, V.M. Wuthrich, \& R.M. Rapee

Pragmatic Case Studies in Psychotherapy, http://pcsp.libraries.rutgers.edu

Volume 9, Module 3, Article 4, pp. 359-370, 10-27-13 [copyright by authors]

\section{Cool Kids School-Based Anxiety Program (Rapee, Lyneham, et al., 2006c)}

The Cool Kids school version is based very closely on the standard clinic version of the program, but it incorporates a modified format to allow delivery within the structure of schools. The primary purpose of the program is also slightly different since school-based delivery of anxiety management programs is often aimed at early intervention or prevention, rather than clinical management. Hence selection of appropriate participants becomes a major issue (see McLoone, Hudson \& Rapee, 2006; McLoone \& Rapee, 2012). The school-based version is designed to be delivered to groups of children only for approximately 8-10 sessions of around 60 minutes (to allow for delivery within one school term) and is supplemented by two parentinformation evenings. Parents and young people receive the same manuals that are used in the standard Cool Kids program since the content and covered skills are identical.

Initial evaluation showed strong outcomes in a population of children aged 4-5 years from especially low socio-economic backgrounds (Mifsud \& Rapee, 2005). However, a subsequent study showed more equivocal results and reflected the difficulties in selecting appropriate children and maintaining optimal engagement among children and parents who are not suffering clinical levels of impairment (McLoone \& Rapee, 2012).

\section{Cool Little Kids Program (Rapee, Lau \& Kennedy, 2010)}

The Cool Little Kids program was aimed at the prevention of emotional disorders (anxiety, depression). The program was developed to target anxious behaviors and risk factors in pre-school children aged 3-6 years. Initial research with the program selected children who scored high on measures of temperamental inhibition (as a key risk factor for anxiety and depression), although more recent work in our clinic is using the same program with preschool children with clinical levels of anxiety. This program includes 6 sessions (90 minute duration) that involve only the parents and is generally run in groups (although individual delivery is possible). In one study we added social skills training directly for the children, but results appeared similar to those achieved with parents only (Lau, Rapee, \& Coplan, 2013). The program includes psychoeducation and parent management training with a particular focus on parental overprotection. It also includes graded exposure, and cognitive restructuring for parental anxious thoughts. As an early intervention program, Cool Little Kids has been demonstrated to reduce the development of anxiety disorders among preschool children one and three years later (Rapee et al., 2005; 2010) and to prevent the development of mood and anxiety disorders among girls by the time they reach adolescence, some 11 years later (Rapee, 2013).

\section{Cool Kids Outreach Program (Lyneham, Wuthrich, \& Rapee, 2010)}

The outreach version of Cool Kids was initially developed for use with geographically isolated rural children who were unable to attend standard treatment with a therapist, but can be used with any young people or families who are unable or unwilling to attend sessions or prefer the convenience of home-based treatment. For children (aged below 13), the program requires delivery by a parent (with the parent as a therapist model). The parent receives a copy of the selfhelp text "Helping Your Anxious Child, 2nd Edition” (Rapee et al., 2008) and the companion 
"Cool Kids" in Denmark: Commentary on a

Cognitive-Behavioral Therapy Group for Anxious Youth

S.J. Perini, V.M. Wuthrich, \& R.M. Rapee

Pragmatic Case Studies in Psychotherapy, http://pcsp.libraries.rutgers.edu

Volume 9, Module 3, Article 4, pp. 359-370, 10-27-13 [copyright by authors]

child workbook (available for download from the internet). These materials can then be supplemented by several sessions between the parent and therapist that are delivered either over the telephone or via emails. Parents are given an outline of how to organize the program, using the text and children's activities over a 12 week period. The parent works through the allotted self-help materials each week and then assists their child to complete the corresponding activities in the child's workbook. This program has demonstrated good efficacy with considerably stronger effects when telephone contact is maintained than when the program is delivered by the parent alone (Lyneham \& Rapee, 2006; Rapee et al., 2006).

A slightly different model for outreach is used with adolescents (aged 13 and above). The Cool Teens program was developed for home use directly by adolescents, with some support from their parents. The Cool Teens program is an eight-module computerized program that teaches adolescents cognitive behavioral skills to manage anxiety and is ideally run over 12 weeks. The program has been traditionally delivered on a CD-ROM and used on the adolescent's home computer; however, it is now available through the internet. The Parent Companion that accompanies the computerized program teaches parents about some of the core anxiety management skills and discusses ways that they can help their adolescents to apply the skills they learn in the computerized program. The Cool Teens materials are best supplemented by brief telephone calls between the therapist and the adolescent and parent. A randomized controlled trial using this program indicated good efficacy among anxious adolescents aged 1418 years (Wuthrich et al., 2012). For more description of the program and its development, see Cunningham et al. (2007; 2009).

\section{Cool Kids Autism Spectrum Disorder Program (Chalfant et al., 2011)}

Although a number of young people with high functioning autism spectrum disorder (ASD) have completed the standard Cool Kids program with success, it became apparent that the special needs of this population would benefit from some minor modifications to the structure and delivery of the material. Hence, the ASD adaptation to Cool Kids was designed for children 7-12 years of age who suffer both from anxiety and high functioning Autism Spectrum Disorder. Anxiety management skills are adapted to suit the learning style of children with Autism and the typical presentation of anxiety in these children. This program emphasizes skills training in relaxation and graded exposure with less emphasis on cognitive restructuring skills and the number of sessions is slightly increased (to 12) to allow slower delivery. A randomized controlled trial has shown good efficacy for this version of the program (Chalfant et al., 2007).

\section{Cool Kids Adolescent Anxiety and Depression Program (Schniering et al., 2006)}

Given the high levels of comorbidity between anxiety and depression, especially among adolescents, a modified program was developed for this population. This program incorporates skills for anxiety management in adolescents together with additional materials to address comorbid depression, such as pleasant event scheduling, negotiation, and conflict resolution. The program is designed for adolescents aged 12-18 years of age who suffer from both anxiety and depression, with either disorder being primary. The program has been run in both individual and group formats and, because the participants are adolescents, therapist time is focused primarily 
"Cool Kids" in Denmark: Commentary on a

Cognitive-Behavioral Therapy Group for Anxious Youth

S.J. Perini, V.M. Wuthrich, \& R.M. Rapee

Pragmatic Case Studies in Psychotherapy, http://pcsp.libraries.rutgers.edu

Volume 9, Module 3, Article 4, pp. 359-370, 10-27-13 [copyright by authors]

on them, with a lower level of involvement from parents. Randomized controlled trials have shown that this program is effective at reducing both anxiety and depression (Schniering \& Rapee, 2013).

\section{COMMENTARY ON THE CASE STUDIES DESCRIBED BY LUNDKVIST-HOUNDOUMADI AND THASTUM}

Lundkvist-Houndoumadi and Thastum (2013a, 2013b) have provided a highly detailed and insightful description of six children treated with the Cool Kids program at their Clinic in Aarhus, Denmark. These case studies include careful descriptions of problems and histories, and clear case formulations for each child. Of particular interest were the clear similarities from these anxious Danish children to our own experiences with childhood anxiety disorders in Australia. Aside from some minor cultural differences, the descriptions could easily have been taken from the case files of our own clients. There was an immediate sense of recognition, especially as we read about some of the treatment challenges encountered-each difficulty reminded us of obstacles we face regularly in our Clinic. The response rate reported, with four out of the six children making significant progress, is also consistent with the outcomes that we typically achieve within group-based treatment in Australia.

The authors present an interesting discussion of the factors that differentiate treatment responders from non-responders. These include both the child's and their parents' motivations for change and engagement with the therapy; the extent to which the families practiced the treatment components systematically and incorporated them into daily life; the presence of family difficulties, such as poor communication between parents and general disorganization; and the extent to which the parents found the group members and structure to be supportive. We agree that these are all relevant factors, and are currently working on improving the standard Cool Kids program to address issues identified as potential obstacles to change. With anxiety such a significant problem for up to $5 \%$ of children and adolescents (Breton et al. 1999), it is important that we continue to revise and improve the program so that more young people can benefit. Whilst the revised version is still in progress, we are happy to discuss some of our ideas here.

\section{Motivation}

A key issue identified by Lundkvist-Houndoumadi and Thastum is that of motivation, on the part of both the parents and the child. Difficulties with motivation are, of course, not unique to the area of child anxiety, and have been identified as barriers to change in a variety of treatment settings. "Motivational Interviewing" was developed from the substance abuse area to enhance readiness for change by helping clients explore and resolve ambivalence (Miller 1983). There is good evidence for its utility in the areas of addictive and health behaviors, and it also appears to improve outcomes when added to other treatment approaches (Hettema, Steele and Miller, 2005). Recent work has begun to incorporate Motivational Interviewing and related techniques to enhance outcomes for anxious adults (Westra, Arkowitz, \& Dozois, 2009). It is possible that Motivational Interviewing may be useful for those parents who are ambivalent about making the changes involved in the Cool Kids program. This could be an optional 
"Cool Kids" in Denmark: Commentary on a

Cognitive-Behavioral Therapy Group for Anxious Youth

S.J. Perini, V.M. Wuthrich, \& R.M. Rapee

Pragmatic Case Studies in Psychotherapy, http://pcsp.libraries.rutgers.edu

Volume 9, Module 3, Article 4, pp. 359-370, 10-27-13 [copyright by authors]

component, used at the therapist's discretion for families who they identify as struggling to maintain motivation to change.

\section{Exposure}

Another change that we are considering is increasing the time spent doing in-session exposure. The Cool Kids program currently has one session devoted to practice of exposure within the session, but we have found additional in-session exposure to be beneficial. As Lundkvist-Houndoumadi and Thastum have identified, some families do minimal practice of therapy tasks, including exposure, outside the treatment sessions. Whether this lack of practice is due to genuine time pressures, a lack of motivation on the part of the parent or child, or the parents' lack of confidence in their own ability to assist their child, increased in-session exposure ensures that all children have at least some opportunity to confront their fears on a regular basis. Additionally, in-session exposure allows therapists to coach parents on the best way to respond to their child when anxious, and show them how to use all of the Cool Kids skills in combination. This can build skill and confidence levels for both parents and children. Finally, in-session exposure is particularly useful for those children who have difficulty identifying their cognitions or even ranking their fears, obstacles identified by Lundkvist-Houndoumadi and Thastum in both treatment responders and nonresponders..

By being present whilst the child attempts exposure, the therapist may gain valuable insight into the processes underlying the child's difficulties.

\section{A Modular Approach to Accommodate Individual Variation}

As the articles illustrate, there is considerable variation in the cases that can present in a child anxiety clinic. In order to accommodate these individual differences, we have experimented with a modular approach to the treatment manual. This means that the manual is divided into two sections-core components, and optional modules. The core components are implemented with every family, and consist of psychoeducation, detective thinking, parenting information, and exposure. The optional modules are used at the therapist's discretion to address individual difficulties that are not covered in the core components. Such modules could include assertiveness training, coping with teasing/bullying, social skills training, parent management of oppositional behaviors, emotion-surfing (similar to mindfulness), parental motivational interviewing, and a module to address sleep difficulties. This modular approach would provide therapists with some flexibility to address particular issues that they identify as a barrier to the child's progress, whilst still ensuring that the essential core components of the program are prioritized.

\section{Group Versus Individual Format}

One difficulty with the modular approach, however, is that it is easier to manage when the program is applied in individual rather than group format. Lundkvist-Houndoumadi and Thastum have written about the benefits of the group setting, noting that four out of six families identified it as a very positive aspect of therapy. In addition to the support and sharing of experiences that the group format provides, another advantage of groups is the reduced cost of 
"Cool Kids" in Denmark: Commentary on a

Cognitive-Behavioral Therapy Group for Anxious Youth

S.J. Perini, V.M. Wuthrich, \& R.M. Rapee

Pragmatic Case Studies in Psychotherapy, http://pcsp.libraries.rutgers.edu

Volume 9, Module 3, Article 4, pp. 359-370, 10-27-13 [copyright by authors]

treating several children at once. It is noteworthy, however, that recent work at our Clinic suggests that we achieve better outcomes when we treat children individually, rather than in a group format. It is possible that some combination of group and individual therapy may be the optimal structure, allowing for the support and cost-effectiveness of group delivery for certain aspects, as well as the flexibility to tailor treatment components to each family's specific needs. Future research should consider methods of combining these therapeutic approaches, the utility of which could be analyzed using both group studies and the type of case study approach demonstrated by Lundkvist-Houdoumadi and Thastum.

\section{Addressing Parental Anxiety Problems}

Lundkvist-Houndoumadi and Thastum identified that some of the parents in their treatment group (Erik’s mother, Tom's father, and Lene’s mother) had experienced significant anxiety and stress themselves. Additionally, a further three of the parents reported a history of depression (Niel's mother, Niel's father, and Tom's mother). Given the strong genetic and familial influences known to contribute to childhood anxiety (Last et al., 1987; Lieb et al., 2000), this is certainly not surprising and it reflects our experience in our own Clinic. Interestingly, Lundkvist-Houndoumadi and Thastum did not find that parental anxiety was one of the factors found to distinguish between treatment responders and non-responders. This differs from previous research that identifies parental anxiety as a significant risk to the successful outcome and maintenance of gains following short-term CBT (Cobham, Dadds \& Spence, 1998; Kendall, Hudson, Gosch, Flannery-Schroeder \& Suveg, 2008).

In a recent attempt to improve outcomes from the Cool Kids program, we tried adding a brief parental anxiety management program (BPAM) to the standard group treatment. This consists of five 45-min group sessions of anxiety management training for the parents, in addition to the Cool Kids group sessions. The main aim of the BPAM component is to teach parents to manage their own anxiety using CBT techniques. It was anticipated that the BPAM sessions would reduce parental anxiety and consequently improve outcomes for their children. Unfortunately, however, this was not the case. In a randomized controlled trial, it was found that participants in the BPAM condition did no better than those in the standard Cool Kids condition, in regards to either parent or child anxiety (Hudson et al, 2013). Potential explanations for this include the brevity of the BPAM component, and the possible complications of integrating child and parent treatment. It may be that parents with anxiety disorders were reluctant to, or found it difficult, to work on their own anxiety when their focus was on their child. As illustrated in the work of Lundkvist-Houdoumadi and Thastum, systematic case studies of clients drawn from the BPAM study might be a very fruitful way to further explore the reasons why the BPAM component was not successful and how it could be modified to work in an effective manner.

\section{The Cost-Effectiveness of Treatment}

Another issue we are exploring in our Clinic in Australia is the efficacy of minimal intensity interventions. We were interested to read that the therapy group described by Lundkvist-Houndoumadi and Thastum was heavily staffed, with a senior psychologist and eight student therapists. Additionally, the treatment included a home visit to each participating family. 
"Cool Kids" in Denmark: Commentary on a

These factors would add to the cost of the treatment, and while possibly increasing the quality of the intervention, may result in the treatment being available to fewer families. Our team has spent several years evaluating minimal intensity interventions, including pure bibliotherapy (selfguided reading materials (Rapee, Abbott, \& Lyneham, 2006); bibliotherapy augmented by telephone or email contact with a therapist (Lyneham \& Rapee, 2006); and bibliotherapy supported by direct therapist contact (Lyneham, Abbott, \& Rapee, 2006). All of these interventions have been shown to produce effects that are significantly better than no treatment and in some cases not significantly different from standard, therapist-led treatment, but all have involved considerably less therapist time and resources than traditional treatment. We note that in some of their other work, the Aarhus group has replicated these effects (Thastum et al., 2013).

Some of our current research involves treating anxious children with a stepped-care approach. Stepped care has been promoted as a framework for healthcare delivery that allows a balance between cost savings and maximum intensity treatment (Bower \& Gilbody, 2005; Davison, 2000; Sobell \& Sobell, 2000). The primary principle is that the least intensive (and generally least expensive) intervention is delivered to an individual initially and the outcome carefully evaluated before more intensive (and costly) treatments are introduced. This method of titrating treatment according to need is expected to provide greater cost-effectiveness than either restriction to low intensity interventions (which minimize resources but sacrifice efficacy) or blanket delivery of high intensity interventions (which maximize efficacy but sacrifice resources). We are currently using a stepped-care approach with young people aged 7-17 in our Clinic, and hope to report on our findings within the next two years.

\section{CONCLUSION}

Anxiety is a common and potentially debilitating problem for young people that requires greater understanding. The management of anxiety disorders in youth has been widely researched over the past decade and some well-validated treatments have now been developed and empirically supported. Nonetheless, up to $40 \%$ of young people remain symptomatic after treatment (James et al., 2006) and greater understanding of barriers to current treatments are necessary. Considered and detailed case studies such as those reported here by LundkvistHoundoumadi and Thastum are tremendously useful to help identify the characteristics of anxious young people and their families that interfere with optimal treatment response. It is only by paying careful attention to such detailed cases that we will begin to produce innovative improvements to current empirically validated interventions.

\section{REFERENCES}

Barrett, P.M., Dadds, M.R., \& Rapee, R.M. (1996). Family treatment of childhood anxiety: A controlled trial. Journal of Consulting and Clinical Psychology, 64 (2), 333-342.

Barrett, P.M., Duffy, A.L., Dadds, M.R., \& Rapee, R.M. (2001). Cognitive-behavioral treatment of anxiety disorders in children: Long-term (6-year) follow up. Journal of Consulting and Clinical Psychology, 69 (1), 135-141.

Bower P.J., \& Gilbody S. (2005). Stepped care in psychological therapies: Access, effectiveness and efficiency: Narrative literature review. British Journal of Psychiatry, 186, 11-17. 
"Cool Kids" in Denmark: Commentary on a

Cognitive-Behavioral Therapy Group for Anxious Youth

S.J. Perini, V.M. Wuthrich, \& R.M. Rapee

Pragmatic Case Studies in Psychotherapy, http://pcsp.libraries.rutgers.edu

Volume 9, Module 3, Article 4, pp. 359-370, 10-27-13 [copyright by authors]

Breton, J. J., Bergeron, L., Valla, J. P., Berthiaume, C., Gaudet, N., Lambert, J., St. Georges, M., Houde, L. \& Lépine, S. (1999). Quebec Child Mental Health Survey: Prevalence of DSM-III-R mental health disorders. Journal of Child Psychology and Psychiatry, 40: 375-384.

Chalfant, A.M., Rapee, R., \& Carroll, L. (2007). Treating anxiety disorders in children with high functioning Autism spectrum disorders: A controlled trial. Journal of Autism \& Developmental Disorders, 37 (10), 1842-1857.

Chalfant, A., Lyneham, H., Rapee, R. M., \& Carroll, L. (2011). Cool Kids child anxiety disorder program: Autism spectrum disorder adaptation: Centre for Emotional Health, Macquarie University, Sydney, Australia.

Cobham, V. E., Dadds, M. R., \& Spence, S. H. (1998). The role of parental anxiety in the treatment of childhood anxiety. Journal of Consulting and Clinical Psychology, 66, 893905.

Cunningham, M. J., Rapee, R. M., \& Lyneham, H. J. (2007). Overview of the Cool Teens CDROM for anxiety disorders in adolescents. The Behavior Therapist, 30, 15-19.

Cunningham, M. J., Wuthrich, V. M., Rapee, R. M., Lyneham, H. J., Schniering, C. A., \& Hudson, J. L. (2009). The Cool Teens CD-ROM for anxiety disorders in adolescents: A pilot case series. European Child \& Adolescent Psychiatry, 18, 125-129.

Davison, G. (2000) Stepped care: Doing more with less? Journal of Consulting and Clinical Psychology, 68, 580 -585.

Hettema, J., Steele, J., \& Miller, W. R. (2005). Motivational interviewing. Annual Review of Clinical Psychology, 1, 91-111

Hudson, J. L., Rapee, R. M., Deveney, C., Schniering, C. A., Lyneham, H. J., \& Bovopoulous, N. (2009). Cognitive behavioral treatment versus an active control for children and adolescents with anxiety disorders: A randomized trial. Journal of the American Academy of Child and Adolescent Psychiatry, 48(5), 533-544.

Hudson, J. L., Newall, C., Rapee, R. M., Lyneham, H. J., Schniering, C. S., Wuthrich, V. M., Schnieder, S., Seeley-Wait, E., Edwards, S., \& Gar, N. S. (2013). The impact of brief parental anxiety management on child anxiety treatment outcomes: A controlled trial. Journal of Clinical Child \& Adolescent Psychology, DOI: 10.1080/15374416.2013.807734

James, A., Soler, A., \& Weatherall, R. (2006). Cognitive behavioural therapy for anxiety disorders in children and adolescents. The Cochrane Library, 1, 1-25.

Kendall, P. C., Hudson, J. L., Gosch, E., Flannery-Schroeder, E., \& Suveg, C. (2008). Cognitivebehavioral therapy for anxiety disordered youth: A randomized clinical trial evaluating child and family modalities. Journal of Consulting and Clinical Psychology, 76, 282297.

Last C. G., Hersen M., Kazdin A. E., Francis G., Grubb H. J.(1987). Psychiatric illness in the mothers of anxious children. American Journal of Psychiatry, 144:1580-83

Lau, E. X., Rapee, R. M., \& Coplan, R. J. (2013). A randomized controlled evaluation of the inclusion of a child component to an early intervention for inhibited pre-schoolers. Manuscript submitted for publication.

Lieb R., Wittchen H. U., Hofler M., Fuetsch M., Stein M. B., \& Merikangas K.R. (2000). Parental psychopathology, parenting styles, and the risk of social phobia in offspring: A prospective-longitudinal community study. Archives General Psychiatry 57(9):859-66 
"Cool Kids" in Denmark: Commentary on a

Lundkvist-Houndoumadi, I. \& Thastum, M. (2013a). A "Cool Kids" cognitive-behavioral therapy group for youth with anxiety disorders: Part 1, The case of Erik. Pragmatic Case Studies in Psychotherapy, 9 (2), Article 3, 122-178. Available: http://hdl.rutgers.edu/1782.1/pcsp_journal

Lundkvist-Houndoumadi, I. \& Thastum, M. (2013b). A "Cool Kids" cognitive-behavioral therapy group for youth with anxiety disorders: Part 2, analysis of the process and outcome of responders versus nonresponders. Pragmatic Case Studies in Psychotherapy, 9 (2), Article 4, 179-274. Available: http://hdl.rutgers.edu/1782.1/pcsp_journal

Lyneham, H. J., Abbott, M. J., \& Rapee, R. M. (2006). Parent Group Supplemented Bibliotherapy for Child Anxiety Disorders. Paper presented at the 40th Annual Convention of Association of Cognitive Behavior Therapy.

Lyneham, H. J., \& Rapee, R. M., (2006). Evaluation of therapist-supported parent-implemented CBT for anxiety disorders in rural children. Behavior Research and Therapy, 44(9), 1287-1300.

Lyneham, H. J., Wuthrich, V. M. \& Rapee, R. M., (2010). The Cool Kids Child and Adolescent Anxiety Program Adaptation for Supported Bibliotherapy Therapist Manual. Centre for Emotional Health, Macquarie University: Sydney, Australia.

McLoone, J., Hudson, J. L., \& Rapee, R. M. (2006). Treating anxiety disorders in a school setting. Education and Treatment of Children, 29(2), 219-242.

McLoone, J. K., \& Rapee, R. M. (2012). Comparison of an anxiety management program for children implemented at home and school: Lessons learned. School Mental Health, 4(4), 231-242.

Mifsud, C., \& Rapee, R. M. (2005). Early intervention for childhood anxiety in a school setting: Outcomes for a disadvantaged population. Journal of the American Academy of Child and Adolescent Psychiatry, 44(10), 996-1004.

Miller, W. R. (1983). Motivational interviewing with problem drinkers. Behavioural Psychotherapy, 11(02), 147-172.

Rapee, R. M. (2000). Group treatment of children with anxiety disorders: Outcome and predictors of treatment response. Australian Journal of Psychology, 52, 125-129.

Rapee, R. M. (2003). The influence of comorbidity on treatment outcome for children and adolescents with anxiety disorders. Behavior Research and Therapy, 41, 105-112.

Rapee, R. M. (2013). The preventative effects of a brief, early intervention for preschool-aged children at risk for internalising: Follow-up into middle adolescence. Journal of Child Psychology and Psychiatry, 54 (7), 780-788.

Rapee, R. M., Abbott, M. J., \& Lyneham, H. J. (2006). Bibliotherapy for Children with Anxiety Disorders Using Written Materials for Parents: A Randomized Controlled Trial. Journal of Consulting and Clinical Psychology, 74, 436-444.

Rapee, R. M., Kennedy, S., Ingram, M., Edwards, S., \& Sweeney, L. (2005). Prevention and early intervention of anxiety disorders in inhibited preschool children. Journal of Consulting and Clinical Pscyhology, 73 (3), 488-497.

Rapee, R. M., Kennedy, S., Ingram, M., Edwards, S., \& Sweeney, L. (2010). Altering the trajectory of anxiety in at-risk young children. American Journal of Psychiatry, 167, 1518-1525. 
"Cool Kids" in Denmark: Commentary on a

Rapee, R. M., Lau, E. X, \& Kennedy S. J. (2010). The Cool Little Kids Anxiety Prevention Program-Therapist Manual. Centre for Emotional Health, Macquarie University: Sydney, Australia

Rapee, R. M., Lyneham, H. J., Hudson, J. L., Kangas, M., Wuthrich, V. M., \& Schniering, C. A. (2012). Effect of comorbidity on treatment of anxious children and adolescents: Results from a large combined sample. Journal of the American Academy of Child \& Adolescent Psychiatry, 51 (1), 47-56.

Rapee, R., Lyneham, H., Schniering, C., Wuthrich, V., Abbott, M., Hudson, J., \& Wignall, A. (2006a). Cool Kids therapist manual: For the Cool Kids child and adolescent anxiety programs. Centre for Emotional Health, Macquarie University: Sydney, Australia.

Rapee, R., Lyneham, H., Schniering, C., Wuthrich, V., Abbott, M., Hudson, J., \& Wignall, A. (2006c). Cool Kids therapist manual: For the Cool Kids child and adolescent anxiety program: School version. Centre for Emotional Health, Macquarie University: Sydney, Australia.

Rapee, R. M., Wignall, A., Spence, S. H., Cobham, V. E., \& Lyneham, H. (2008). Helping your anxious child: A step-by-step guide for parents (2nd ed.). Oakland, CA: New Harbinger

Schniering, C. A., \& Rapee, R. M. (2013) Managing comorbidity in youth: Evaluation of a transdiagnostic treatment for adolescents with concurrent anxiety and depression. Manuscript in preparation.

Schniering, C. A., Rapee, R. M., Lyneham, H. J., Wuthrich, V., Hudson J. L., \& Wignall, A. (2006). The Cool Kids ${ }^{\circledR}$ Adolescent Anxiety \& Depression Program Therapist Manual. Centre for Emotional Health, Macquarie University University: Sydney, Australia.

Sobell, M. \& Sobell, L. (2000) Stepped care as a heuristic approach to the treatment of alcohol problems. Journal of Consulting and Clinical Psychology, 68, 573 -579.

Thastum, M., Jørgensen, L., Schneevoigt-Matthiesen, S. M., Clausen T., Vadgaard, T., \& Arendt, K. (2013). Therapist assisted bibliotherapy for children with anxiety disorders: preliminary results of a randomized controlled trial. Paper presented at the World Congress of Behavioural and Cognitive Therapies, Lima, Peru.

Westra, H. A., Arkowitz, H., \& Dozois, D. J. (2009). Adding a motivational interviewing pretreatment to cognitive behavioral therapy for generalized anxiety disorder: A preliminary randomized controlled trial. Journal of Anxiety Disorders, 23(8), 1106-1117.

Wuthrich, V. M., Rapee, R. M., Cunningham, M. J., Lyneham, H. J., Hudson, J. L., \& Schniering, C. A. (2012). A randomized controlled trial of the Cool Teens CD-ROM computerized program for adolescent anxiety. Journal of the American Academy of Child \& Adolescent Psychiatry, 51 (3), 261-270. 
Volume 9, Module 3, Article 4, pp. 359-370, 10-27-13 [copyright by authors]

Table 1: Overview of Cool Kids programs

\begin{tabular}{|c|c|c|c|c|c|c|}
\hline Program Name & $\begin{array}{l}\text { Age } \\
\text { Group }\end{array}$ & Family Dyad & Setting & Therapy Format & $\begin{array}{l}\text { Group or } \\
\text { Individual }\end{array}$ & Sessions \\
\hline Cool Kids Anxiety Program & $7-18$ & Family & Community & Face to Face & Both & $10 \times 2$ hour sessions \\
\hline $\begin{array}{l}\text { Cool Kids School-Based Anxiety } \\
\text { Program }\end{array}$ & $7-18$ & $\begin{array}{l}\text { Children alone with } \\
\text { two Parent Evenings }\end{array}$ & School & Face to Face & Group & $\begin{array}{l}10 \times 1 \text { hour sessions }+2 \times \\
2 \text { hour parent evenings }+ \\
1-2 \text { individual } \\
\text { consultations with parents }\end{array}$ \\
\hline Cool Little Kids Program & $3-6$ & Parent only & Community & Face to Face & Group & $6 \times 2$ hour sessions \\
\hline Cool Kids Outreach Program & $7-13$ & Parent and Child & Home & $\begin{array}{l}\text { Bibliotherapy with therapist } \\
\text { telephone support }\end{array}$ & Individual & 12 weeks \\
\hline $\begin{array}{l}\text { Cool Teens Computerized } \\
\text { Program }\end{array}$ & $13-18$ & $\begin{array}{l}\text { Adolescent with } \\
\text { support from Parent }\end{array}$ & Home & $\begin{array}{l}\text { Computerized with therapist } \\
\text { telephone support }\end{array}$ & Individual & 8 modules over 12 weeks \\
\hline $\begin{array}{l}\text { Cool Kids Autism Spectrum } \\
\text { Disorder Program }\end{array}$ & $7-12$ & Family & Community & Face to Face & Both & $12 \times 2$ hour sessions \\
\hline $\begin{array}{l}\text { Cool Kids Adolescent Anxiety } \\
\text { and Depression Program }\end{array}$ & $12-18$ & Family & Community & Face to Face & Both & $12 \times 2$ hour sessions \\
\hline
\end{tabular}

